\title{
Hybrid stent implantation to the pulmonary artery from peripheral access via recruited systemic-pulmonary shunt
}

\author{
Ireneusz Haponiuk ${ }^{1,2}$, Maciej Chojnicki², Mariusz Steffens ${ }^{2}$, Radosław Jaworski², Konrad Paczkowski², \\ Aneta Szofer-Sendrowska ${ }^{2}$, Katarzyna Gierat-Haponiuk ${ }^{3}$
}

${ }^{1}$ Chair of Physiotherapy, Gdansk University of Physical Education and Sport, Gdansk, Poland

${ }^{2}$ Department of Pediatric Cardiac Surgery, Mikolaj Kopernik Hospital, Gdansk, Poland

${ }^{3}$ Department of Rehabilitation, Medical University of Gdansk, Gdansk, Poland

Postep Kardiol Inter 2015; 11, 1 (39): 48-49

DOI: $10.5114 /$ pwki.2015.49185

\begin{abstract}
A bstract
The implantation of vascular stents in patients with low body weight and difficult anatomy of the stenosis needs individual cannulation strategy or a hybrid approach. We present a successful balloon angioplasty with direct stent implantation to severe ostial stenosis of the left pulmonary artery to xenograft anastomosis (LPA) in a 6-year-old boy late after surgical correction of pulmonary atresia with ventricular septal defect. Peripheral approach to LPA was possible after surgical rethoracotomy and the recruitment of a left Blalock-Taussig (BT) shunt stump. The cooperation of cardiovascular intervention with surgical approach appears a safe strategy for borderline patients referred for staged treatment of complex congenital heart defects.
\end{abstract}

Key words: congenital heart defects, hybrid treatment.

Despite the clinical value of a balloon angioplasty with direct stent implantation and technological progress, the procedure is still only possible in optimal anatomical conditions. The gold standard is peripheral vessel cannulation. Nevertheless, in individual patients with very low body weight or unfavourable location of stenosis, there is a need to design an individual strategy for stent implantation, as well as to choose a hybrid approach [1].

A 6-year-old boy (20 kg body weight) in the long-term follow up after staged treatment for pulmonary atresia with ventricular septal defect (PA-VSD), initially after bilateral systemic-to-pulmonary shunts (BT dex and sin), and finally the surgical correction with the use of pulmonary valved conduit Contegra 12 (Medtronic, USA), underwent control echocardiography (TTE) that showed a severe ostial left pulmonary artery (LPA) stenosis in the area of its anastomosis with xenograft conduit. Attempts to perform a percutaneous angioplasty from peripheral access were ineffective because of the morphology of the stenosis (sharp angle of LPA origin). The patient was referred for hybrid stent implantation with surgical approach from the distal part of the LPA [2].
The approach was left-sided posterolateral rethoracotomy with meticulous preparation of pleural adhesions and the closure of aorto-pulmonary collateral arteries (MAPCAs). A systemic-to-pulmonary shunt (Gore-Tex $4 \mathrm{~mm}, \mathrm{LM}$ Gore and Associates, USA), closed by vascular clips during anatomic correction of PA-VSD, was identified parallel to the descending aorta. After removing the clips, the shunt was rinsed in $0.9 \%$ saline, and a vivid blood flow from the pulmonary artery was obtained. An arterial sheath was introduced via Blalock-Taussig (BT) shunt stump, and angiography was performed. The LPA stenosis was identified between the place of anastomosis of the xenograft conduit and the distal part of the LPA, with morphology typical for native stenosis (Figure 1). When the balloon dilatation catheter was introduced in the right position, hybrid angioplasty of the LPA was performed. The stenosis dilatation was unsatisfactory because of the elasticity of the stenotic artery. After the exchange of the balloon catheter, a vascular stent $(18 \mathrm{~mm}$ long $\times 10 \mathrm{~mm}$ diameter, Cook, EU) was directly implanted in the right position. An effective LPA dilatation was achieved with improved blood flow to the left lung from

\section{Corresponding author:}

Ireneusz Haponiuk, Department of Pediatric Cardiac Surgery, Mikolaj Kopernik Hospital, 1-6 Nowe Ogrody St, 80-803 Gdansk, Poland, phone: +48 58 7640490, e-mail: ireneusz_haponiuk@poczta.onet.pl

Received: 2.10.2014, accepted: 26.01.2015. 


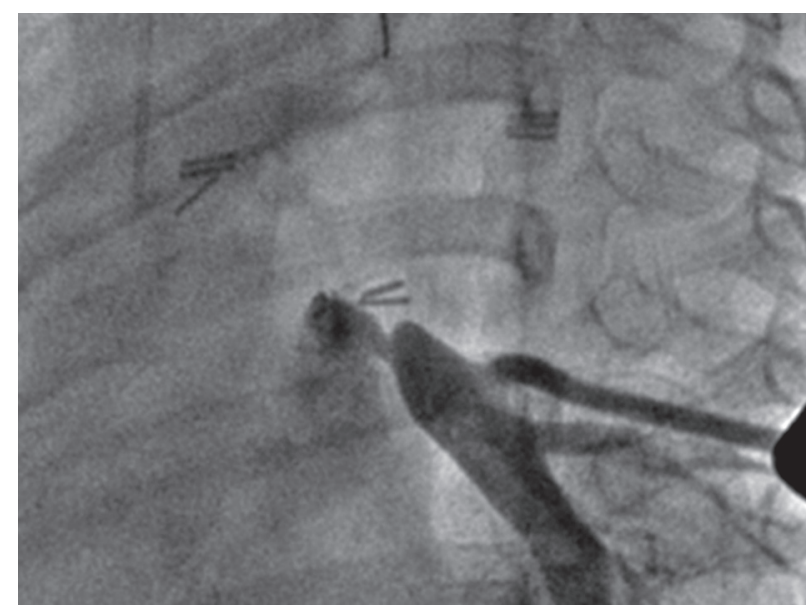

Figure 1. Intraoperative angiography: stenosis of left pulmonary artery (LPA) in the area of anastomosis with xenograft conduit; the patient is a 6-year-old boy after anatomic correction of pulmonary atresia with ventricular septal defect (PA-VSD)

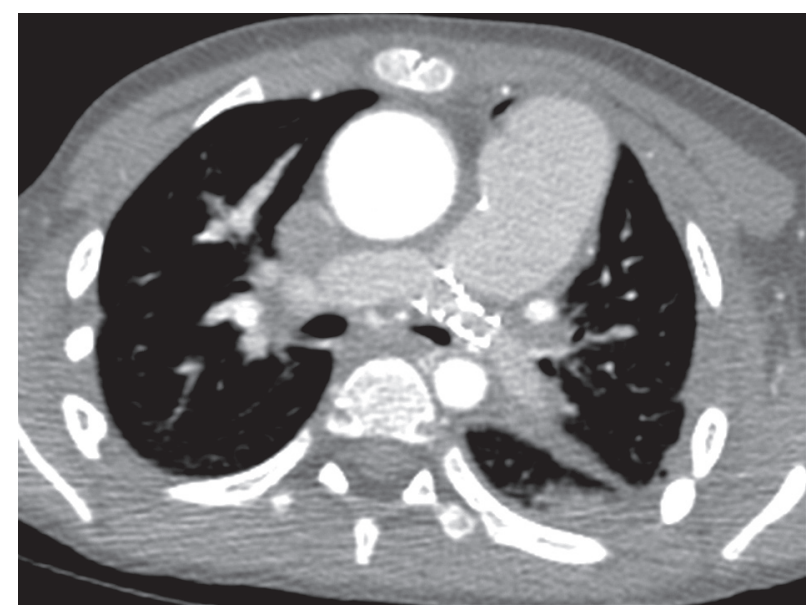

Figure 3. Control angio-CT: proper position of implanted stent to left pulmonary artery (LPA)

the mean pulmonary artery (Figure 2). Local bleeding from a rapture of the LPA wall was controlled and careful haemostasis was effectively performed. Drainage of the pleural cavity was done in a routine fashion. Control transesophageal echocardiography (TEE) showed an effective blood flow to the LPA without residual pressure gradients. The correct position of the implanted stent was confirmed by an angio-computed tomography (CT) scan, performed on the 6th postoperative day before discharge (Figure 3).

The hybrid stent implantation to the LPA via recruited systemic-to-pulmonary shunt became a successful alternative method that enabled the elimination of the classic peripheral access limitations. The cooperation of cardiovascular intervention with surgical approach appears to

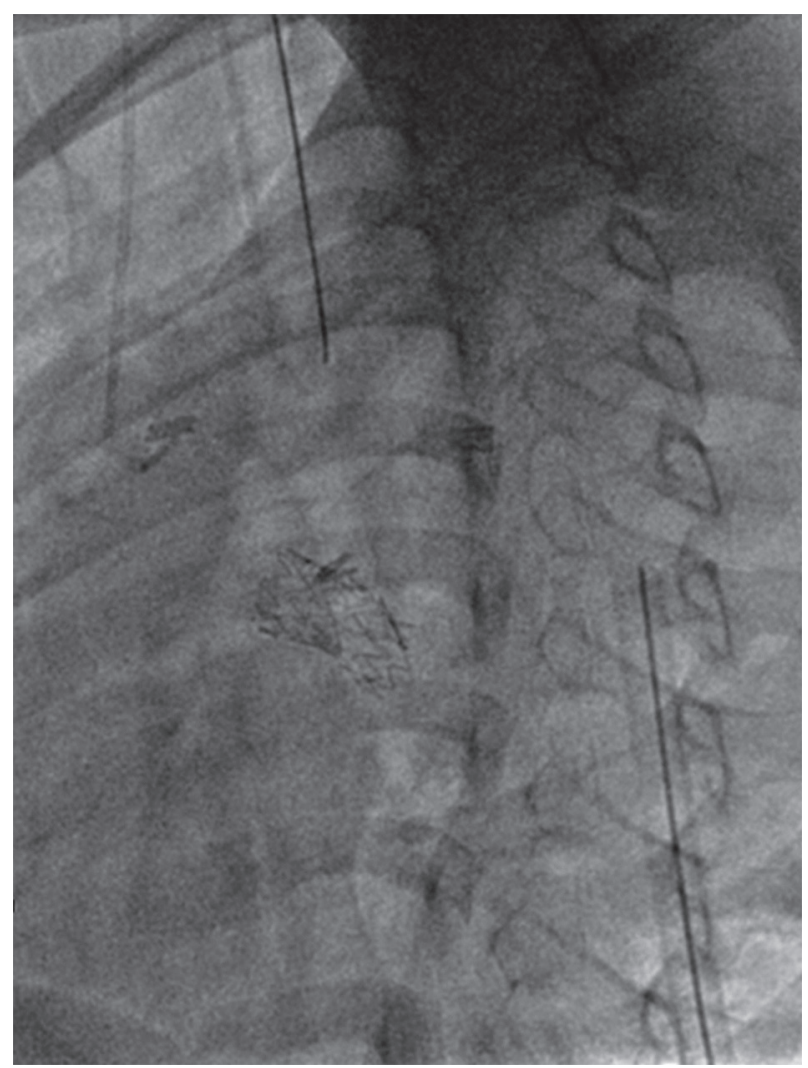

Figure 2. Intraoperative angiography: vascular stent implantation with an effective left pulmonary artery (LPA) dilatation via peripheral access

be an original and safe strategy for borderline patients referred for staged treatment of complex congenital heart defects.

\section{Conflict of interest}

The authors declare no conflict of interest.

\section{References}

1. Ayegnon KG, Borgoend E, Bourguignon T, et al. Hybrid intra-operative pulmonary artery stenting in congenital heart disease. Indian J Thorac Cardiovasc Surg 2011; 27: 169-73.

2. Menon SC, Cetta F, Dearani JA, et al. Hybrid intraoperative pulmonary artery stent placement for congenital heart disease. Am J Cardiol 2008; 102: 1737-41. 